\title{
COVID-19 and Kounis Syndrome: Deciphering Their Relationship
}

\author{
Nicholas G. Kounis ${ }^{1}$, Ioanna Koniari²®, Cesare de Gregorio ${ }^{3} \oplus$ \\ ${ }^{1}$ Department of Cardiology, Patras University School of Medicine, Patras, Greece \\ ${ }^{2}$ Department of Cardiology, University Hospital of South Manchester NHS Foundation Trust, Manchester, UK \\ ${ }^{3}$ Department of Clinical and Experimental Medicine, University of Messina Medical School, Messina, Italy
}

Coronavirus infection is not a newly discovered condition. Currently, 7 coronaviruses that can cause human disease have been identified. Coronaviruses hCoV-HKU1, hCoV-OC43, hCoVNL63, and hCoV-229E can principally cause asymptomatic or mild respiratory and gastrointestinal infections accounting for approximately $5-30 \%$ of common colds. ${ }^{1}$ In the last 2 decades, 3 human coronaviruses resulted in outbreaks that raised considerable global health concerns. These include the severe acute respiratory syndrome coronavirus (SARS-CoV), the Middle East respiratory syndrome coronavirus (MERS-CoV), and the current new human coronavirus, SARS-CoV-2 that has rapidly spread from Wuhan in China to over 223 countries and regions in the world, causing a global pandemic affecting 114 million people with over 2.5 million deaths by March 1, 2021, with a case fatality ratio ranging from 1 to $3.5 \%$ in most countries. ${ }^{2}$ Interestingly, these highly pathogenic human coronaviruses have evolutionarily acquired the ability to encode numerous proteins, allowing them to escape recognition and response by the immune system, while they can simultaneously enable inflammatory and immune cell overactivation inducing a cytokine storm. ${ }^{3}$ Severe systemic complications such as coagulopathy with thromboses, acute cardiac/coronary injury such as myocardial infarction and stent thrombosis, brain or liver injury, and multiple organ dysfunction have been associated with the cytokine storm and cytokine release syndrome, increasing the risk of mortality (Table 1). Various types of cytokines have been associated with the cytokine storm, including interleukins, chemokines, interferons, tumor necrosis factors, and colony-stimulating factors. The cytokine storm can occur as a result of inappropriate recognition, for instance, in case of hypersensitivity or an ineffective response due to immune evasion. ${ }^{4}$ Indeed, a storm of proinflammatory cytokines that can lead to catastrophic events and to Kounis acute hypersensitivity-associated syndrome has been encountered in human anaphylaxis with profuse hypotension or hypoxemia. ${ }^{5,6}$

\section{Anaphylaxis and Cytokines A Common Pathway Toward Kounis Syndrome}

In severe anaphylaxis accompanied by hypotension or hypoxemia, a range of mediators - similar to those of the cytokine storm in coronavirus disease 2019 (COVID-19) patients - are reported to increase in both animal models and in vitro cell stimulation studies. ${ }^{6}$ In immune-mediated anaphylaxis and in the COVID-19 cytokine storm, the implicated molecules are released from inflammatory cells and include IL-1 $\alpha$, IL-1 $\beta$, IL-6, IL-10, IL-17A, IL-12 p70, IL-18, IFN $\alpha$, TNF, and an additional inflammatory cluster defined by thrombopoietin, IL-33, IL-16, IL-21, IL-23, IFN $\lambda$, eotaxin, and eotaxin-3, demonstrating an increased correlation with severe disease. ${ }^{7}$ Furthermore, a marked increase in multiple type 2 effectors, namely interleukin-5 (IL-5), IL-13, immunoglobulin E (IgE), eosinophils, and type 2 antibody isotype $\operatorname{IgE}$, was found in severe COVID-19 disease; the increase continued during the course of the disease. ${ }^{7,8}$ Eosinophils and basophils are activated by monocyte chemotactic protein 3 , which is the most effective activating chemokine. ${ }^{9}$ Dendritic cells may also initiate autoimmune responses and stimulate $\mathrm{T}$ cells, resulting in macrophage activation. ${ }^{10}$ Interactions between lymphocytes, monocytes, macrophages, and mast cells can increase vascular permeability, via release of TNF, IL-1 $\beta$, IL-6, CXCL8 (IL-8), macrophage migration inhibitory factor, CCL2 (also known as monocyte chemoattractant protein-1 (MCP1)), high-mobility group box-1 protein, and matrix metalloproteinases. ${ }^{11}$ The latter can promote plaque disruption or rupture, leading to myocardial infarction via activation of their zymogen forms such as interstitial collagenase, gelatinase, and stromelysin. ${ }^{12}$ All types of inflammatory cells participate in an inflammatory vicious cycle in which they can activate each other, like a "ball of thread," via multidirectional signals (Figure 1). For example, mast cells can activate $\beta$ macrophages and may enhance T-cell activation. Inducible macrophage protein 1a may activate mast cells, while

Address for correspondence: Nicholas G. Kounis, Department of Cardiology, Patras University School of Medicine, Patras, Greece

e-mail: ngkounis@otenet.gr

Received: April 13, 2021 Accepted: April 23, 2021 • DOI: 10.5152/balkanmedj.2021.21097

Available at www.balkanmedicaljournal.org

ORCID iDs of the authors: N.G.K. 0000-0002-9751-6710; I.K. 0000 -0002-1033-5299; C.d.G. 0000-0003-3022-266X

Cite this article as:

Kounis NG, Koniari I, de Gregorio C. COVID-19 and Kounis syndrome: Deciphering their relationship. Balkan Med J. 2021; 38(3):145-149.

Copyright@Author(s) - Available online at http://balkanmedicaljournal.org/ 
TABLE 1. Symptoms and signs of Cytokine storm

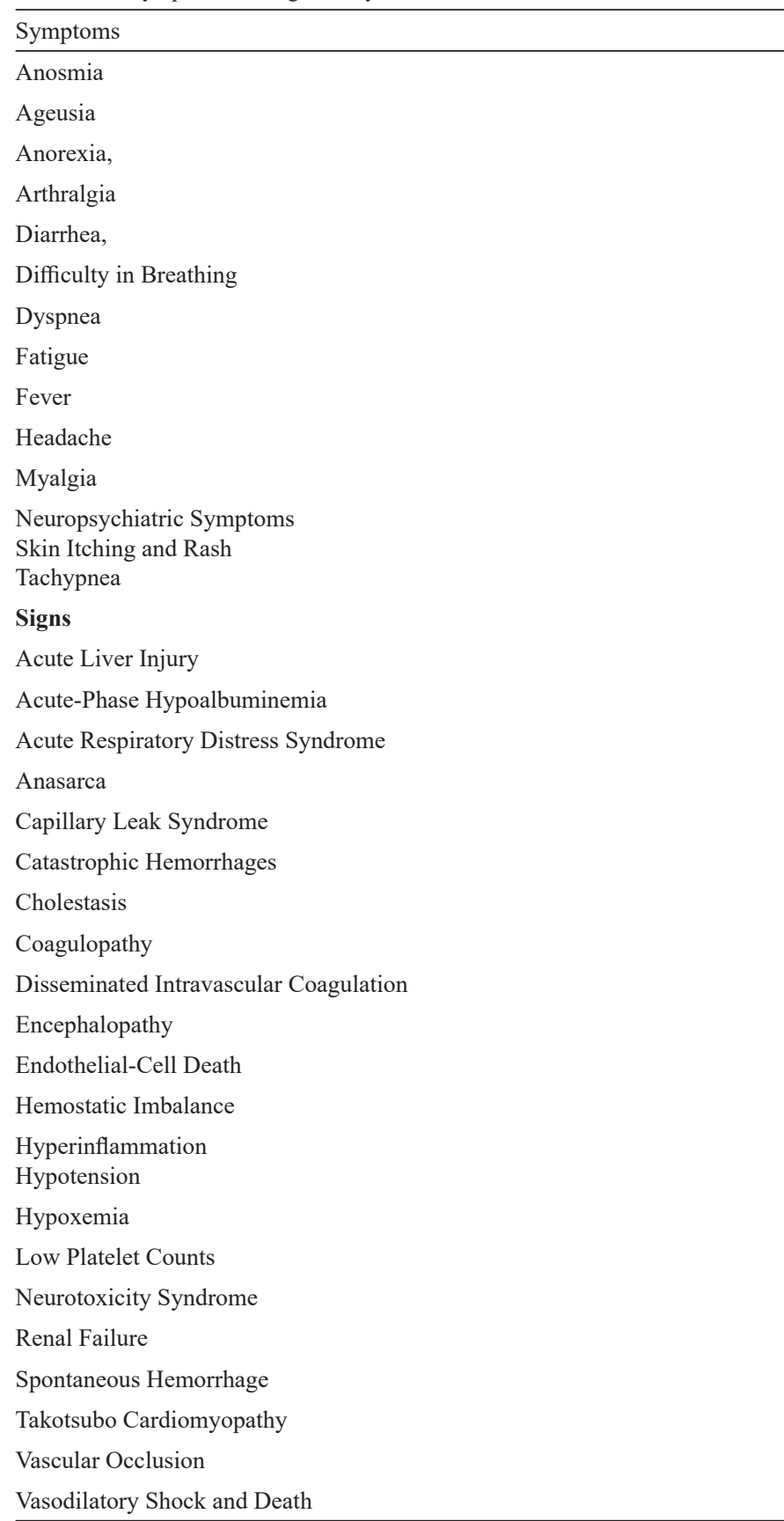

CD169- macrophages activate CD8 T cells. T cells may mediate mast cell activation and proliferation and further regulate macrophage activity. ${ }^{6}$

\section{Mast Cells and COVID-19}

Mast cells constitute a key source of proinflammatory cytokines in COVID-19.12 These cells are typically activated by allergic triggers, but they can also be triggered by virus-associated molecular patterns, via activation of toll-like receptors (TLRs), including SARS$\mathrm{CoV}-2$, in order to release a variety of proinflammatory mediators such as IL-6 and IL-1 $\beta$, thus potentially contributing to COVID-19 pathology. ${ }^{13}$ These cells enter the circulation from bone marrow as mononuclear cell precursors and circulate as mast cell precursors, disposing in their surface KIT receptors (cytokine receptors) for stem cell factor (SCF). SCF is a major cytokine which is essential for mast cell growth, survival, differentiation, proliferation, adhesion, and homing. Mast cells can adhere to all human tissues, even to the brain tissue that does not suffer from allergic reactions because IgE antibodies cannot cross the blood-brain barrier (BBB). Therefore, they differentiate and mature in these tissues, a process that might take several days to occur or even weeks. On the contrary, basophils mature in bone marrow from granulocyte precursors and enter the circulation as mature cells; they do not go into the tissues except during the late stage of an allergic reaction. Mast cells are located perivascularly in the coronary arteries where they can mature under the influence of local micro-environmental factors, resulting in different phenotypes.

Mast cells can be typically activated via the following pathways:

a. By allergens cross-linking allergen-specific $\operatorname{IgE}$ bound to high affinity Fc epsilon receptor $1 .^{6}$

b. By non-IgE-mediated mast cell degranulation via activation of the complement C1q, C3a C4, C5a, and Factor B, which are called anaphylatoxins. This complement pathway activation involves IL-5 and tryptase and is much more common than recognized, in patients who develop renal failure or fatal cerebral events. ${ }^{14}$

c. By the low affinity mas-related $\mathrm{G}$ protein-coupled receptor X2 (MRGPRX2) that may activate mast cells via non-Fce receptors. ${ }^{14}$

d. By neuropeptides, including corticotropin-releasing hormone, neurotensin (NT), and substance P (SP) via high-affinity receptors. $^{15}$

In complement and MRGPRX2 direct mast cell activation, the specific IgEs may remain undetected, and tryptase levels may be normal, even in a condition as serious as the Kounis syndrome.

Following activation, mast cells rapidly secrete the preformed, granule-stored, heparin, histamine, tryptase, and TNF, as well as newly synthesized leukotrienes, PAF, prostaglandin D2, cytokines, and chemokines that are released 6-24 hours later. Mast cell-derived vasoactive mediators, especially cytokines, can also increase the permeability of the BBB that explains the SARSCoV-2 "COVID-19 brain fog" either directly via activation of mast cells or by permitting cytokines to enter through a disrupted BBB. ${ }^{16}$

It has been proposed that co-stimulation of human and rodent mast cell populations in vitro with FceRI and certain TLRs can induce release of the above described proinflammatory mediators, suggesting another mechanism through which bacterial or viral infections might exacerbate atopic asthma and other IgE- and mast cell-associated disorders such as Kounis syndrome in vivo. ${ }^{17}$

\section{Kounis syndrome and COVID-19}

The allergic angina syndrome, representing a manifestation of endothelial dysfunction or microvascular angina that belongs to 


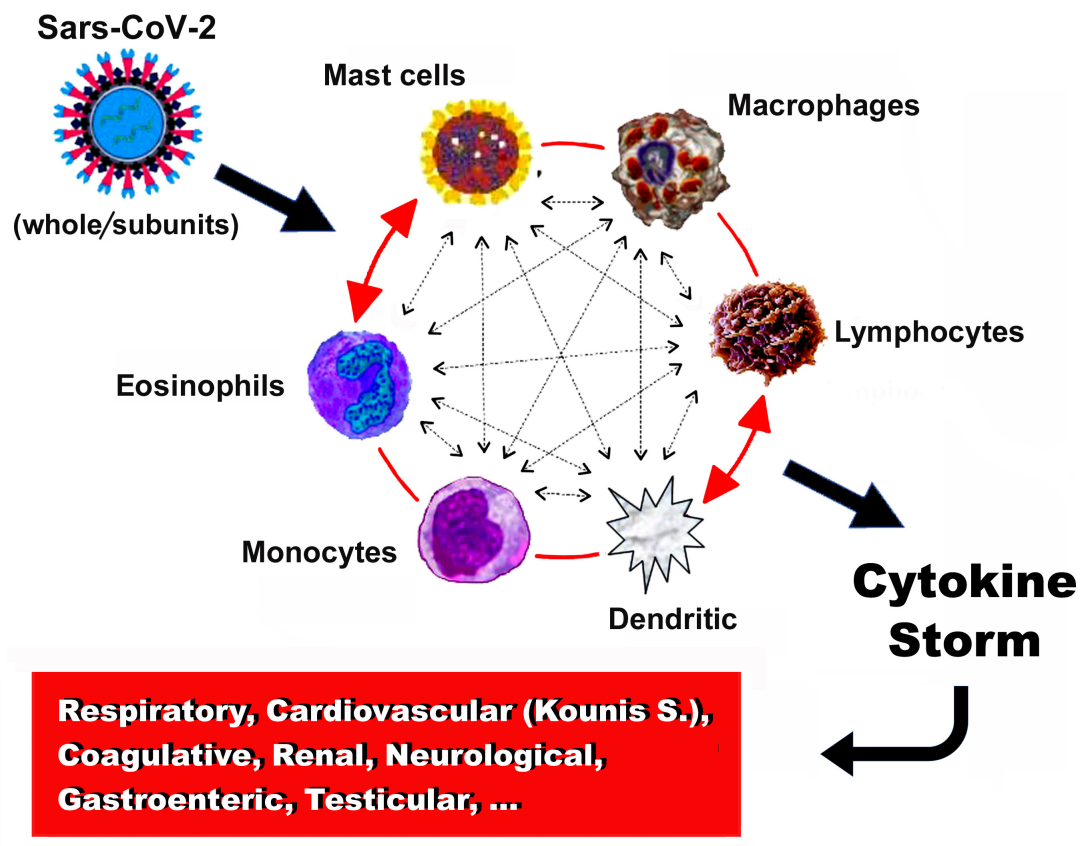

FIG. 1. The vicious cycle of inflammatory cells that activate each other like a "ball of thread".

the group of myocardial infarctions with nonobstructive coronary arteries (MINOCA), was described some 30 years ago and was named by American researchers as the Kounis syndrome, in 2005. ${ }^{6,18}$ The pathophysiology of this syndrome includes inflammatory mediators released during an anaphylactic event from mast cells that are activated according to the above described 4 types of mast cell activation. In such an activation cascade, other interacting cells including T-lymphocytes, macrophages, eosinophils, monocytes, and dendritic cells can also participate. Despite the fact that mast cells are a numerical minority in this inflammatory cascade, they do decisively influence the inflammatory process. Additionally, platelets also participate via activation of their corresponding receptors by thromboxane, histamine, and platelet-activating factor. Moreover, platelets also express high-affinity IgE fragment crystallizable (FceRI), low-affinity IgE FceRII/CD23, and lowaffinity $\operatorname{IgG} \mathrm{Fc} \gamma \mathrm{RIIA} / \mathrm{CD} 32$ receptors ${ }^{19}$ that constitute potential targets for many antigens.

The SARS-CoV-2 invades the endothelial cells that contain ACE-2 receptors. The ACE-2 receptors constitute the main pathways through which the virus enters the endothelial cells. ACE-2 metabolizes angiotensin II to the vasodilatory and antiinflammatory peptide angiotensin. Entry of the SARS-CoV-2 into the endothelial cells, especially in the early phases of the infection, interrupts the metabolism of angiotensin II, which further results in increased angiotensin II levels that induce a significant proinflammatory-cytokine release, leading to a cytokine storm..$^{20}$ Angiotensin II can exert several prothrombotic effects such as vasoconstriction, endothelial and platelet activation, and proinflammatory cytokine release.
As noted above, serum cytokine levels are elevated in both COVID-19 and in Kounis acute hypersensitivity-associated syndrome. The following indicate and support the view of etiopathogenetic similarities between COVID-19 associated with cytokine storm and Kounis /MINOCA, and thrombotic variants:

1. COVID-19 affects the coronary arterial tree as it can induce coronary spasm, direct endothelial or vascular injury, plaque rupture and microthrombi, hypoxic injury, cytokine storm, and a higher than expected incidence of stent thrombosis, that is attributed to the underlying hypercoagulable state that clinically coincides with the main 3 Kounis syndrome variants namely coronary spasm, acute myocardial infarction, and stent thrombosis. ${ }^{21}$

2. COVID-19 is associated with an increase in effector cells including IgEs and eosinophils. ${ }^{7}$

3. Antihistamines (famotidine, rupatadine, ebastine) that block histamine receptors, and corticosteroids (dexamethasone) which are potent anti-inflammatory and immunomodulating agents, are the drugs of choice for treating both COVID-19 and Kounis syndrome. ${ }^{20}$

4. COVID-19-induced activation of the immune system in asymptomatic subjects could increase the risk of conversion from asymptomatic, subclinical, or atherosclerotic disease into an unstable state with vulnerable plaques prone to thrombosis, as in Kounis syndrome. ${ }^{23}$

5. COVID-19-induced cytokine storm and hypercoagulopathy can present with large cerebral vessel occlusion and 
Kounis syndrome as a result of increased risk of fatal arterial thrombosis. ${ }^{24}$

6. COVID-19 cardiac arrest due to Prinzmetal's angina resembling Kounis syndrome in a previously normal heart has been described recently. ${ }^{25}$

7. Cerebral venous sinus and other body organ thromboses with thrombocytopenia have been reported, especially in women, following adenoviral Ad26.COV2.S and ChAdOx1 nCov-19 vaccination. Heparin platelet factor 4 (PF4) antibody was positive, nearly in all patients, unrelated to heparin use. ${ }^{26}$ Although the presence of antibodies that may represent a link between the immune response to the vaccines and the clotting syndromes has been already speculated, ${ }^{27}$ the mechanisms of PF4 complex formation leading to thrombus creation have not been elaborated.

PF4 is a highly positive protein present in the a-granules of platelets that can quickly bind and neutralize heparin. The pair PF4/ heparin has antigenic properties and induces anti-PF4/heparin antibodies of IgG class but the reason of its action as autoantigen remains largely unclear. PF4-heparin-IgG complex antibodies have been detected in $3.1-4.4 \%$ of healthy subjects.

The heparin-PF4-IgG immune complex can cause thrombosis, via activation of the specific low affinity Fc $\gamma$ RIIa receptors on the platelet surface whereas platelet surface brings additional high affinity for IgE FceRI and low affinity for IgE FceRII/CD32 receptors. ${ }^{28}$

Heparin is naturally occurring glycosaminoglycan (GAG), thus is not required to be given externally to cause thrombosis. PF4 has ability to bind to cell-surface GAGs and other negatively charged molecules and forms complexes with heparin and also with dextran sulfate and fucoidan which contain sulfate groups per monosaccharide residue.GAG heparin is found exclusively in mast cells whilst heparan sulphate is expressed on the surface of mast cells and play important part in regulating of allergic inflammation. ${ }^{29}$

The raised question is why thromboses occur only with these 2 vaccines and also only in women. Is any common path that connects these 2 conditions?

Only these vaccines contain polysorbate excipient-a mixture of esters and etherates synthesized by oleic acid, ethylene oxide, sorbitan and isosorbide that abound in creams, lotions, and cosmetics and mainly used by women. These polysorbate components can induce hypersensitivity reactions and hemolysis. Anaphylaxis and acute heparin-induced thrombocytopenia (HIT) have occurred in a patient with heparin-induced antibodies. ${ }^{30}$ Indeed, in this patient the antibodies were exclusively IgGs!

Therefore, the cascade of GAG heparins, polysorbate and sulfates, could explain the "non heparin" HIT-like thrombus formation. ${ }^{31} \mathrm{We}$ believe that confirmation of this assumption and application of diagnostic measures e.g. skin prick tests to polysorbate and preventive measures e.g. avoidance vaccines that contain polysorbate especially in women who mainly use products that contain polysorbate might solve this very serious problem.

Author Contributions: Concept - N.G.K.; Literature Review - I.K.; Writing - N.G.K.; Critical Review - C.d.G.

Conflict of Interest: The authors have no conflicts of interest to declare.

Funding: The authors declared that this study had received no financial support.

\section{REFERENCES}

1. Zhu Z, Lian X, Su X et al. From SARS and MERS to COVID-19: A brief summary and comparison of severe acute respiratory infections caused by three highly pathogenic human coronaviruses. Respir Res. 2020;21(1):224. ([CrossRef]

2. Hopkins J Coronavirus Resource Center (available at: https://coronavirus.jhu.edu/ data/mortality March 1, 2021)

3. Ye Q, Wang B, Mao J. The pathogenesis and treatment of the 'cytokine Storm' in COVID-19. J Infect. 2020;80(6):607-613. [CrossRef]

4. Fajgenbaum DC, June CH. Cytokine Storm. N Engl J Med. 2020 ;383(23):2255-2273. [CrossRef]

5. Stone SF, Cotterell C, Isbister GK, Emergency Department Anaphylaxis Investigators et al. Elevated serum cytokines during human anaphylaxis: identification of potential mediators of acute allergic reactions. $J$ Allergy Clin Immunol. 2009;124(4):786-92.e4. [CrossRef]

6. Kounis NG, Koniari I, Velissaris D, Tzanis G, Hahalis G. Kounis syndrome-not a single-organ arterial disorder but a multisystem and multidisciplinary disease. Balk Med J. 2019;36(4):212-221. [CrossRef]

7. Lucas C,Wong $\mathrm{P}$, Klein J et al. Longitudinal analyses reveal immunological misfiring in severe COVID-19. Nature. 2020;584(7821):463-469. [CrossRef]

8. Chen N, Zhou M, Dong X et al. Epidemiological and clinical characteristics of 99 cases of 2019 novel coronavirus pneumonia in Wuhan, China: a descriptive study. Lancet. 2020;395(10223):507-513. [CrossRef]30211-7)

9. Dahinden CA, Geiser T, Brunner T et al. Monocyte chemotactic protein 3 is a most effective basophil- and eosinophil-activating chemokine. JExp Med. 1994;179(2):751756. [CrossRef]

10. Ferenbach D, Hughes J. Macrophages and dendritic cells: What is the difference? Kidney Int. 2008;74(1):5-7. [CrossRef]

11. Dollery CM, Libby P. Atherosclerosis and proteinase activation. Cardiovasc Res. 2006;69(3):625-635. [CrossRef]

12. Newby AC. Metalloproteinases promote plaque rupture and myocardial infarction: A persuasive concept waiting for clinical translation. Matrix Biol. 2015;44-46:157-166. [CrossRef]

13. Theoharides TC. Potential association of mast cells with coronavirus disease 2019 Ann Allergy Asthma Immunol. 2021;126(3):217-218. [CrossRef]

14. Khan S. Mast cell tryptase level should be checked in all patients with suspected Kounis syndrome. Eur Heart J. 2020;41(31):3018. [CrossRef]

15. Theoharides TC. Neuroendocrinology of mast cells: challenges and controversies. Exp Dermatol. 2017;26(9):751-759. [CrossRef]

16. Theoharides TC, Conti P. COVID-19 and multisystem inflammatory syndrome, or is it mast cell activation syndrome? J Biol Regul Homeost Agents. 2020;34(5) :16331636. [CrossRef]

17. Galli SJ, Tsai M. Mast cells in allergy and infection: versatile effector and regulatory cells in innate and adaptive immunity. Eur J Immunol. 2010;40(7):1843-1851. [CrossRef]

18. Rich MW. Is vasospastic angina an inflammatory disease? Am J Cardiol 2005;96(11):1612. [CrossRef]

19. Hasegawa S, Tashiro N, Matsubara T, Furukawa S, Ra C. A comparison of FcepsilonRI-mediated RANTES release from human platelets between allergic patients and healthy individuals. Int Arch Allergy Immunol. 2001;125(suppl 1):42-47. [CrossRef]

20. Kounis NG, Koniari I, de Gregorio $\mathrm{C}$ et al. Allergic reactions to current available COVID-19 vaccinations: pathophysiology, causality, and therapeutic considerations. Vaccines (Basel). 2021;9(3):221. [CrossRef]

21. Prieto-Lobato A, Ramos-Martínez R, Vallejo-Calcerrada N, Corbí-Pascual M, Córdoba-Soriano JG. A case series of stent thrombosis During the COVID-19 pandemic. JACC Case Rep. 2020;2(9):1291-1296. [CrossRef] 
2 2. Saba L, Gerosa C, Wintermark M et al. COVID19 trigger the plaque vulnerability-a Kounis syndrome warning for "asymptomatic subjects". Cardiovasc Diagn Ther. 2020;10:1352-1355.

2 3. Ertekin A. Triggered by Covid-19? Large vascular occlusion resulting in cytokine Storm syndrome and Kounis syndrome: A case report. J Biomed Res Environ Sci. 2021;2:030-033.

2 4. Wang M, Talon A, Saririan M. Covid-19 cardiac arrest due to Prinzmetal's angina in a previously normal heart. Authorea. March 28, 2021. [CrossRef]

2 5. Greinacher A, Thiele T, Warkentin TE et al. Thrombotic thrombocytopenia after ChAdOx1 nCov-19 Vaccination. $N$ Engl J Med. 2021 April 9. [CrossRef]

26. See I, Su JR, Lale A et al. US Case Reports of Cerebral Venous Sinus Thrombosis With Thrombocytopenia After Ad26.COV2.S Vaccination, March 2 to April 21, 2021. JAMA.COV2. 2021;26:e217517. [CrossRef] [Epub ahead of print].
27. Karron RA, Key NS, Sharfstein JM. Assessing a rare and serious adverse event following administration of the Ad26.COV2.S vaccine. JAMA. 2021. [CrossRef] [Epub ahead of print]

28. Hasegawa S, Tashiro N, Matsubara T, Furukawa S, Ra C. A comparison of FcepsilonRI-mediated RANTES release from human platelets between allergic patients and healthy individuals. Int Arch Allergy Immunol. 2001;125(suppl 1):42-47. [CrossRef]

29. Rose MJ, Page C. Glycosaminoglycans and the regulation of allergic inflammation. Curr Drug Targets Inflamm Allergy. 2004 ;3(3):221-225. [CrossRef]

30. Hewitt RL, Akers DL, Leissinger CA, Gill JI, Aster RH. Concurrence of anaphylaxis and acute heparin-induced thrombocytopenia in a patient with heparin-induced antibodies. J Vasc Surg. 1998 ;28(3):561-565. [CrossRef]

31. Kounis NG, Soufras GD, Almpanis G, Tsigkas G, Mazarakis A. Acute stent thrombosis and heparin induced thrombocytopenia: another manifestation of kounis syndrome? Korean Circ J. 2013 ;43(4):221-222. [CrossRef] 